\title{
Effect of Electroless Copper Coating on the Corrosion Behavior of Aluminium Based Metal Matrix Composites Reinforced with Silicon Carbide Particles
}

\author{
Mohamed Zakaulla', A. R. Anwar Khan², P. G. Mukunda ${ }^{3}$ \\ ${ }^{1}$ Ghousia College of Engineering, Ramanagaram, India \\ ${ }^{2}$ Mechanical Engineering Department, Ghousia College of Engineering, Ramanagaram, India \\ ${ }^{3}$ Mechanical Engineering Department, Nitte Menakshi Institute of Technology, Bangalore, India \\ Email: mohd zakaulla@yahoo.co.in
}

Received October 8, 2013; revised November 23, 2013; accepted December 2, 2013

Copyright (C) 2014 Mohamed Zakaulla et al. This is an open access article distributed under the Creative Commons Attribution License, which permits unrestricted use, distribution, and reproduction in any medium, provided the original work is properly cited. In accordance of the Creative Commons Attribution License all Copyrights (C) 2014 are reserved for SCIRP and the owner of the intellectual property Mohamed Zakaulla et al. All Copyright (C) 2014 are guarded by law and by SCIRP as a guardian.

\begin{abstract}
The present paper involves firstly in the studies of corrosion properties of Al 6061 metal matrix composites reinforced with varying percentage of uncoated and $\mathrm{Cu}$ coated silicon carbide in $3.5 \mathrm{wt} \% \mathrm{NaCl}$ solution using weight loss method. The processing route used for the composites was stir casting technique. Mass loss and corrosion rate measurements were utilized as criteria for evaluating the corrosion behavior of composites. The surface morphology of composites after the corrosion test is determined by using scanning electron microscopy. It has been observed that copper as reinforcement coating reduces the corrosion resistance of composites in comparison to uncoated reinforcements and monolithic alloy.
\end{abstract}

\section{KEYWORDS}

Stir Casting; Al6061; Corrosion Rate; Electroless; Polarization

\section{Introduction}

Aluminium alloy reinforced with silicon carbide particulate possesses a wide variety of properties, including high specific strength and stiffness, controlled thermal expansion coefficient, non-toxic, nonmagnetic, high corrosion resistance, improved high temperature properties, improved wear and abrasion resistance [1-3]. Reinforcement influences corrosion rate, which is one of the main disadvantages in the use of metal matrix composite. This is important in aluminium alloy based composite, where a protective oxide film reduces corrosion rate. Discontinuities in film are due to addition of reinforcement phase, which increases the number of sites where corrosion can be initiated and makes the composite more susceptible to corrosion [4]. Published data [5-8] indicate that the addition of $\mathrm{SiC}$ particles does not appear to enhance corrosion resistance on some aluminium alloys because pits were found to be more on the composites than on the base alloys. All metals and alloys undergo corrosion, which is outlined as the destructive attack of a metal by chemicals, atmosphere and electrochemical processes. The driving force is the free energy of reaction of the metal to make, generally a metal oxide. Since corrosion reactions usually occur on the metal surface, they're referred to as interfacial processes. To achieve high interface bonding strength, wettability of $\mathrm{SiC}$ particle with molten aluminium is important. Unfortunately the wettability of $\mathrm{SiC}$ with molten aluminium is poor. Electroless coating of SiC with nickel [9] and copper has been successively used to prevent undesired interfacial reactions. Copper is added to aluminium alloys to enhance their hardness, strength, creep resistances, fatigue and machinability [10-13]. Copper generally reduces resistance to corrosion in specific compositions and material conditions $[14,15]$. The susceptibility of the Al-Cu alloys towards corrosion decreases in the order of: $\mathrm{Al}>\mathrm{Al}-3 \mathrm{wt} \%$ $\mathrm{Cu}>\mathrm{Al}-9 \mathrm{wt} \% \mathrm{Cu}>\mathrm{Al}-6 \mathrm{wt} \% \mathrm{Cu}$ [14]. The aim of paper is to study and compare the corrosion behaviour of 
uncoated and $\mathrm{Cu}$ coated $\mathrm{SiC}$ composites produced by stir casting technique in marine environment using weight loss method.

\section{Experimental Procedure}

\subsection{Electroless Copper Coating on Silicon Carbide Particles}

The Electroless copper coating on silicon carbide particles relies on sequence of cleaning, sensitizing, activating and plating. The conditions used are detailed in Tables 1 and 2.

\subsection{Processing}

In this study, matrix selected was Al6061 which is procured in form of Ingots. The experimental setup for making cast composite consists of mechanical stirrer and a electrical resistance furnace. About $3 \mathrm{~kg}$ of $\mathrm{Al} 6061$ was melted in a crucible using electrical resistance furnace. Degassing was carried out while molten metal was kept in a electrical resistance furnace at about 700 deg Celsius. The mechanical stirrer was then inserted in to molten metal and rotated to create necessary vortex. Copper coated sic particles (containing 30\% copper as coating) were added to vortex at approx. rate of $50 \mathrm{~g} /$ min and stirring was done for 10 mins and stirrer was taken out of crucible. The melt was taken out of furnace and poured in to permanent moulds.

\subsection{Corrosion Testing}

The corrosion tests was conducted at room temperature

Table 1. Steps in electroless copper coating.

\begin{tabular}{ccccc}
\hline Step & process & Chemical & concentration & Time (min) \\
\hline 1 & cleaning & Deionised water & - & 10 \\
2 & Sensitization & $\mathrm{SnCl}_{2} \mathrm{HCl}$ & $20 \mathrm{~g} / \mathrm{l}, 80 \mathrm{ml} / \mathrm{l}$ & 15 \\
3 & Rinse & Deionised water & - & 10 \\
4 & Activation & $\mathrm{PdCl}_{2} \mathrm{HCl}$ & $1 \mathrm{~g} / \mathrm{l}, 5 \mathrm{ml} / \mathrm{l}$ & 20 \\
5 & Rinse & Deionised water $^{2}$ & - & 10 \\
6 & Copper coating & See Table 2 & & 30 \\
\hline
\end{tabular}

Table 2. Electroless copper solution.

\begin{tabular}{cc}
\hline Chemical & Concentration \\
\hline Copper sulphate $\left(\mathrm{CuSo}_{4} \cdot 5 \mathrm{H}_{2} \mathrm{O}\right)$ & $20 \mathrm{~g} / \mathrm{l}$ \\
Sodium hydroxide & $20 \mathrm{~g} / \mathrm{l}$ \\
Potassium sodium tartrate & $100 \mathrm{~g} / \mathrm{l}$ \\
$\mathrm{Na}_{2}$ EDTA & $20 \mathrm{~g} / \mathrm{l}$ \\
Formaldehyde. & $20 \mathrm{ml} / \mathrm{l}$ \\
\hline
\end{tabular}

using the conventional weight loss method .The specimens for the test were prepared to size of outer dia $18 \mathrm{~mm}$, inner dia $2 \mathrm{~mm}$ and thickness $3 \mathrm{~mm}$ after which the sample surfaces were grounded with abrasive papers starting from grades 400, 800, 1000 and 1500 respectively. The samples were degreased with acetone and then rinsed in distilled water before immersion in still solutions of 3.5\% $\mathrm{NaCl}$ solution. Concentration of $3.5 \% \mathrm{NaCl}$ was preferred for this test since it accelerated corrosion test similar to marine environment. Solution was prepared by dissolving 227.5 gms of solid $\mathrm{NaCl}$ in $6500 \mathrm{~cm}^{3}$ of de-ionized water. The normality of solution is $0.6 \mathrm{~N}$. Each specimen was first weighed before being immersed in $3.5 \% \mathrm{NaCl}$ solution and later taken out after 72, 144, 216, 288 and $360 \mathrm{~h}$ respectively. After the specified time, the heavy corrosion deposits on the surface of samples were removed mechanically, and then the samples were cleaned with distilled water, rinsed with acetone, dried and weighed. The corresponding changes in the weights were noted. At least three samples were tested and average value was taken. The weight loss was measured and Converted into corrosion rate expressed in mils penetration per year (mpy). Mass loss $\left(\mathrm{mg} / \mathrm{cm}^{2}\right)$ for each sample was evaluated by dividing the weight loss (measured using a four decimal digit electronic weighing balance) by its total surface area which is in accordance with ASTM G31 standard recommended practice.

\section{Results and Discussion}

\subsection{SEM/XRD Analysis}

A SEM image of copper coated silicon carbide particles is shown in Figure 1. The image clearly shows that the copper is coated on surface of angular silicon carbide particles. Electroless coating method was used to coat copper on silicon carbide particles.

X-ray diffraction studies (Figure 2) clearly indicate the presence of copper on $\mathrm{SiC}$ and it is noted that after Electroless coating process the peak corresponding to $\mathrm{Cu}$ is present and indicates successful $\mathrm{Cu}$ deposition on $\mathrm{SiC}$

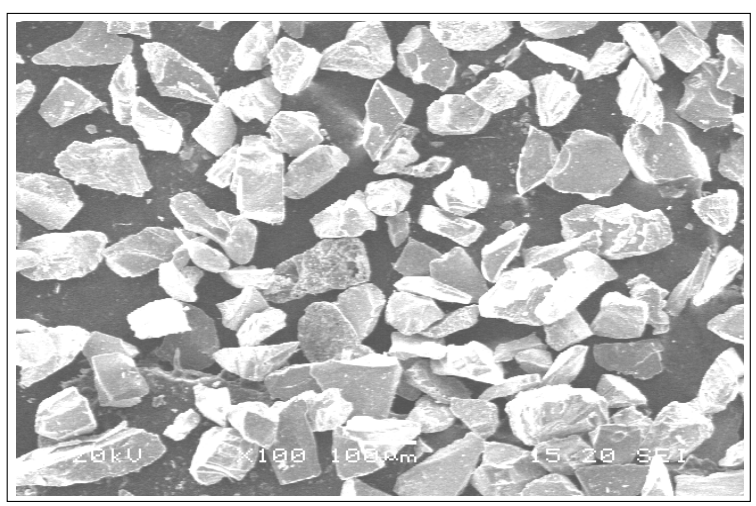

Figure 1. SEM image of Cu-coated SiC particles. 
particle surface.

Figure 3 shows the corrosion rate mpy as a function of exposure time in static immersion test. It can be seen that there is decrease in corrosion rate with increase in duration of exposure to $3.5 \mathrm{wt} \% \mathrm{NaCl}$ solutions implying that the corrosion resistance of materials tested increases as exposure time is increased. The phenomenon of gradually decreasing corrosion rate is due to the formation of passive films on surface of samples. Kennethe Alaneme [8] obtained similar results in $\mathrm{SiC}_{\mathrm{P}}$ reinforced aluminium alloy composites that the corrosion resistance of $\mathrm{Al}-\mathrm{SiC}_{\mathrm{P}}$ composites increased as the exposure time is increased and it was discovered that the nature of passive films formed on the composites was sufficiently stable to reduce significantly the corrosion rate. It is observed that corrosion resistance of $\mathrm{Cu}$ coated $\mathrm{SiC}$ composites decreases in compare to uncoated $\mathrm{SiC}$ composites and base alloy because since $\mathrm{SiC}$ is coated with copper which is a conducting material, it increases the ratio of local cathode area around $\mathrm{SiC}$ particle where low resistance area exists and electrons easily leave from these area, therefore corrosion progress around $\mathrm{SiC}$ particles where pits extend at surface not in depth. This indicates that inter-

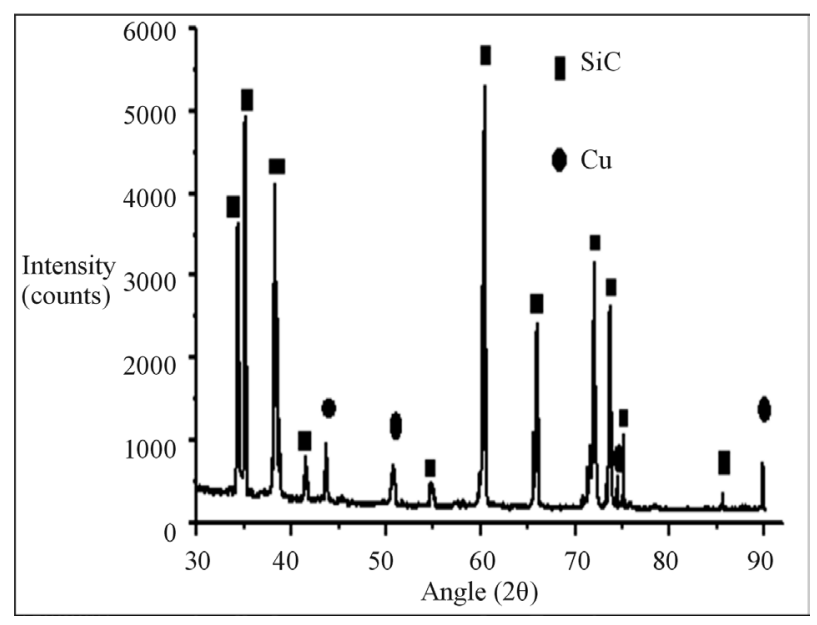

Figure 2. XRD of copper-coated silicon carbide particles.

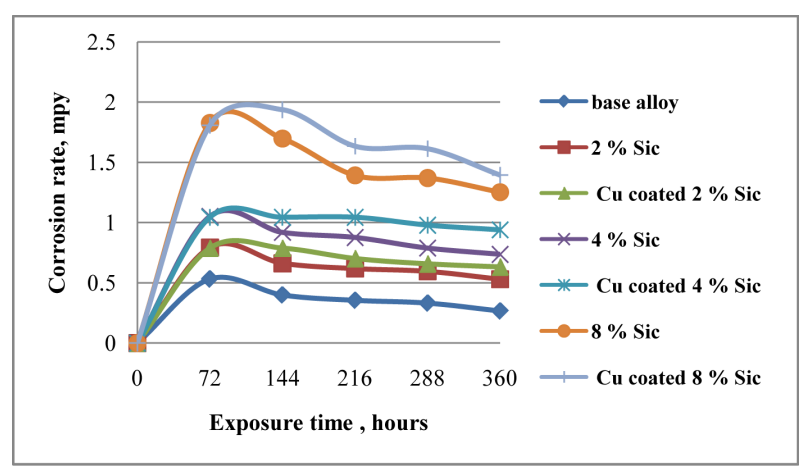

Figure 3. Corrosion rate of $\mathrm{Cu}$ coated and uncoated SiC composites in $3.5 \mathrm{wt} \% \mathrm{NaCl}$ solution. metallic phase $\mathrm{Al}_{2} \mathrm{Cu}$ is more susceptible to corrosion degradation.

Figure 4 shows the mass loss versus time of tested specimens immersed in $3.5 \mathrm{wt} \% \mathrm{NaCl}$ solution. It is observed in this case that mass loss increased with the increase in weight percent of uncoated and $\mathrm{Cu}$ coated $\mathrm{SiC}$. $\mathrm{Cu}$ coated $8 \% \mathrm{SiC}$ composite has a highest mass loss value $\left(0.401 \mathrm{mg} / \mathrm{cm}^{2}\right)$ and the monolithic alloy $(0.074$ $\mathrm{mg} / \mathrm{cm}^{2}$ ) had the least mass loss followed by the $2 \mathrm{wt} \%$ SiC composite $\left(0.148 \mathrm{mg} / \mathrm{cm}^{2}\right)$. Burak Dikici et al. [9] in their work on corrosion behaviour of $\mathrm{Ni}$ Coating of $\mathrm{SiC}$ particles reinforced $\mathrm{Al}$ based MMCs state that $\mathrm{Al} / \mathrm{SiC}$ interfaces are active sites where corrosion at early stages starts in-depth and later as a result of excessive polarisation, expanses to the surface, which indicate that the type of corrosion is pitting and such corrosion behaviour has been attributed to the conductivity of the coating material. According to them, despite improving the wettability, Electroless nickel coating is not an effective method to improve the corrosion resistance in halide solution. A. Pardo et al. [16] in their work on Effect of Reinforcement Coating on Corrosion Behavior of AA-6061/SiC/ 20p Composite found that Corrosion resistance decreased with the use of the silicon dioxide $\left(\mathrm{SiO}_{2}\right)$ active coatings on silicon carbide $(\mathrm{SiC})$ reinforcement particles and the matrix/SiCp interfaces acted as preferential nucleation sites, but the corrosion process was of low intensity. The use of active coatings on reinforcement particles improved wettability by molten aluminum, despite some slight loss of corrosion resistance. D. Mandal et al. [17] in their research on corrosion behaviour of uncoated, copper and nickel coated short steel fiber reinforced $\mathrm{Al}$ composites in $1 \mathrm{~N} \mathrm{NaCl}$ solution stated that corrosion rate was higher for copper coated fiber reinforced composites compared to uncoated fiber and nickel coated fiber reinforced composites.

\subsection{Corrosion Morphology}

After 24 hours of corrosion test it was observed that

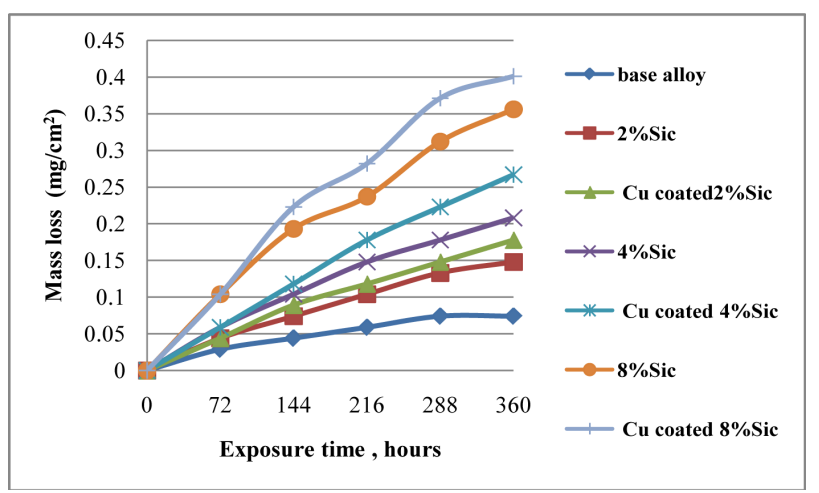

Figure 4. Mass loss of $\mathrm{Cu}$ coated and uncoated SiC composites in $3.5 \mathrm{wt} \% \mathrm{NaCl}$ solution. 
formation of pits were more rapid in $\mathrm{Cu}$ coated $\mathrm{SiC}$ composites than uncoated SiC composites and pits initiation started at $\mathrm{SiC} /$ matrix interface which are active sites because of copper coating. This was reason for max corrosion rate at the beginning and pits expand to the surface. As the test progresses there is a formation of passive films which gradually decreases the corrosion rate. Figure 5 is a SEM micrograph of $8 \%$ uncoated SiC composite exposed to $3.5 \mathrm{wt} \% \mathrm{NaCl}$ solution after $144 \mathrm{~h}$ exposure where at $\mathrm{SiC} /$ matrix interface, preferential localised corrosion can be seen and corrosion starts in depth and later expands to surface. Figure 6 shows the paths where corrosion progresses on corroded surface of composite. Here SiC particles are partially detached at pits which are present at $\mathrm{SiC} /$ matrix interface. Figure 7 at high magnification reveals that the removal of matrix material around $\mathrm{Cu}$ coated 8\% SiC particles after 360 hour exposure. This fig indicates that $\mathrm{SiC}$ particles are not greatly affected by corrosion process. The corrosion progresses on aluminium rich matrix leading to an intense porous structure and aluminium grain boundaries which are closer to $\mathrm{Al} / \mathrm{SiC}$ interface act as the active sites due to copper coating which propagate around the region of

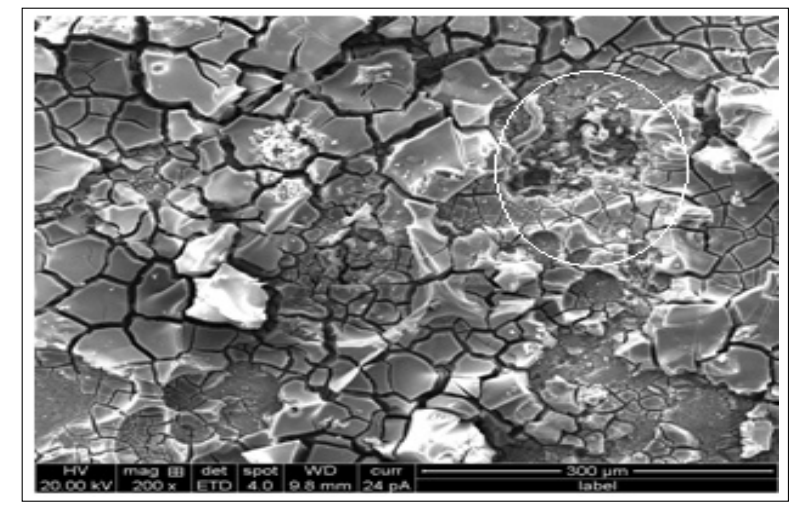

Figure 5. SEM micrograph showing the corroded surface of sample with presence of fresh pit.

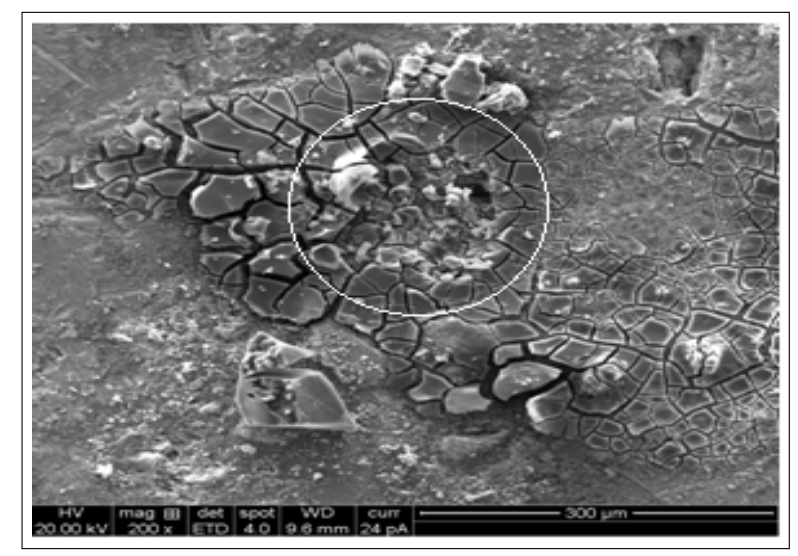

Figure 6. SEM micrograph showing the intensive stage of corrosion having growing pit.

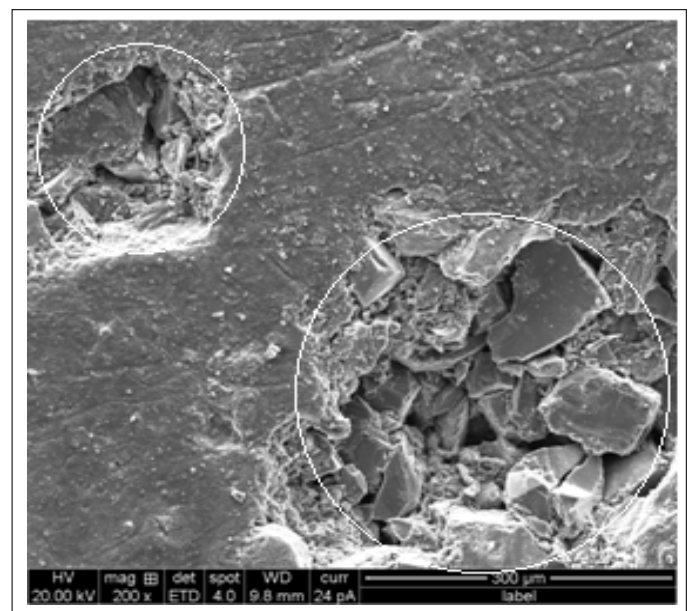

Figure 7. SEM micrograph of $\mathrm{Cu}$ coated $8 \%$ SiC composite after the corrosion test.

$\mathrm{Al} / \mathrm{SiC}$ interface and consequently spread out.

\section{Conclusions}

1) Corrosion rate decreases with increasing in duration of exposure to $3.5 \mathrm{wt} \% \mathrm{NaCl}$ solutions implying that the corrosion resistance of materials tested increases as exposure time is increasing.

2) At early stages, corrosion starts in depth as observed at $\mathrm{Al} / \mathrm{SiC}$ interface which is active sites and later due to excessive polarisation, expands to surface which indicate that corrosion type is pitting.

3) Corrosion rate increases with increasing in wt fraction of uncoated and $\mathrm{Cu}$ coated SiC.

4) $\mathrm{Cu}$ coated $8 \% \mathrm{SiC}$ recorded a max corrosion rate of 1.937 mpy in $3.5 \mathrm{wt} \% \mathrm{NaCl}$ solution.

5) It is observed that Electroless Cu coating is not an effective method to improve the corrosion resistance in structural applications despite improving the wettability of SiC.

\section{REFERENCES}

[1] N. A. Abd Alameer, "Studying the Effect of Chemical Solution on Corrosion Behavior of $\mathrm{SiC}$ and $\mathrm{Al}_{2} \mathrm{O}_{3}$ Reinforced Aluminum Composite Materials,” Journal of Engineering \& Technology, Vol. 29, No. 15, 2011, pp. 3194-3203.

[2] K. H. W. Seah, M. Krishna, V. T. Vijayalakshmi and J. Uchil, "Corrosion Behavior of Garnet Particulate Reinforced LM 13 Al Alloy MMCs," Corrosion Science, Vol. 44, No. 5, 2002, pp. 917-925.

http://dx.doi.org/10.1016/S0010-938X(01)00099-3

[3] G. M. Pinto, J. Nayak and A. N. Shetty, "Corrosion Behavior of 6061 Al-15 vol. Pct. SiC Composite and Its Base Alloy in a Mixture of 1:1 Hydrochloric and Sulphuric Acid Medium,” International Journal of Electrochemical Science, Vol. 4, No. 10, 2009, pp. 1452-1468. 
[4] A. J. Trowsdate, B. Noble, S. J. Haris, I. S. R. Gibbins, G. E. Thompson and G. C. Wood, "The Influence of Silicon Carbide Reinforcement on the Pitting Behavior of Aluminium," Corrosion Science, Vol. 38, No. 2, 1996, pp. 177-191. http://dx.doi.org/10.1016/0010-938X(96)00098-4

[5] J. F. McIntyre, R. K. Conrad and S. L. Golledge, "Technical Note: The Effect of Heat Treatment on the Pitting Behavior of SiCw/AA2124,” Corrosion, Vol. 46, No. 11, 1990, pp. 902-905. http://dx.doi.org/10.5006/1.3580856

[6] J. Wu, W. Liu, P. Li and R. Wu, "Effect of Matrix Alloying Elements on the Corrosion Resistance of SiC/Al Composites Materials," Journal of Materials Science Letters, Vol. 12, No. 33, 1993, pp. 1500-1501.

[7] W. Neil and C. Garrard, "The Corrosion Behaviour of Aluminium-Silicon Carbide Composites in Aerated 3.5\% Sodium Chloride,” Corrosion Science, Vol. 36, No. 5, 1994, pp. 837-851. http://dx.doi.org/10.1016/0010-938X(94)90174-0

[8] K. Alaneme, "Corrosion Behaviour of Heat-Treated Al$6063 / \mathrm{SiC}_{\mathrm{p}}$ Composites Immersed in $5 \mathrm{wt} \% \mathrm{NaCl}$ Solution,” Leonardo Journal of Sciences, Vol. 18, No. 18, 2011, pp. 55-64.

[9] B. Dikici1, C. Tekmen, M. Gavgali and U. Cocen, "The Effect of Electroless Ni Coating of SiC Particles on the Corrosion Behavior of A356 Based Squeeze Cast Composite," Journal of Mechanical Engineering, Vol. 57, No. 1, 2011, pp. 11-20. http://dx.doi.org/10.5545/sv-jme.2010.111

[10] Deonath and P. K. Rohatgi, "Cast Aluminium Alloy Composites Containing Copper-Coated Ground Mica Particles,” Journal of Material Science, Vol. 16, No. 6, 1981, pp. 1599-1606. http://dx.doi.org/10.1007/BF02396877

[11] S.-C. kim, M.-T. Kim, S. Lee, H. Chung and J.-H. Ahn,
"Effects of Copper Addition on Sintering Behavior and Mechanical Properties of Powder Processed Al/SiC Composites,” Journal of Material Science, Vol. 40, No. 2, 2003, pp. 441-447.

[12] A. M. Davidson and D. Regener, "A Comparison of Aluminium-Based Metal Matrix Composites Reinforced with Coated and Uncoated Particulate Silicon Carbide,” Composite Science and Technology, Vol. 60, No. 6, 2000, pp. 865-869.

[13] A. Urena, J. Rams, M. Campo and M. Sánchez, "Effect of Reinforcement Coatings on the Dry Sliding Wear Behavior of Aluminium/SiC Particles/Carbon Fibres Hybrid Composites,” Wear, Vol. 266, No. 11-12, 2009, pp. 11281136.

[14] A. E. Al-Rawajfeh and S. M. A. Al Qawabah, "Investigation of Copper Addition on the Mechanical Properties and Corrosion Resistance of Commercially Pure Aluminum," Emirates Journal for Engineering Research, Vol. 14, No. 1, 2009, pp. 47-52.

[15] J. Zhu and L. H. Hihara, "Corrosion of Continuous Alumina-Fibre Reinforced Al-2 wt.\% Cu-T6 Metal-Matrix Composite in 3.15 wt.\% NaCl Solution," Corrosion Science, Vol. 52, No. 2, 2010, pp. 406-415. http://dx.doi.org/10.1016/j.corsci.2009.09.028

[16] A. Pardo, A. Ureña, S. Merino, et al., "Effect of Reinforcement Coating on Corrosion Behavior of AA6061/ SiC/20p Composite in High Relative Humidity Environments," Corrosion Science, Vol. 60, No. 10, 2004, pp. 945-953. http://dx.doi.org/10.5006/1.3287828

[17] D. Mandal, B. K. Dutta and S. C. Panigrahi, "Influence of Coating on Short Steel Fiber Reinforcements on Corrosion Behavior of Aluminium Base Short Steel Fiber Reinforced Composites," Journal of Materials Science, Vol. 42, No. 8, 2007, pp. 2796-2801. http://dx.doi.org/10.1007/s10853-006-0188-3 